\title{
Period Active Ingredient Dose Total
}

National Cancer Institute

\section{Source}

National Cancer Institute. Period Active Ingredient Dose Total. NCI Thesaurus. Code C95342.

The total amount of active ingredient in all doses of treatment in a given period of time. 